\title{
The Effect of Intellectual Property Rights Protection on the International Competitiveness of the Pharmaceutical Manufacturing Industry in China
}

\author{
Jiaoli Cai ${ }^{1,2 *}$, Hongzhong Zhao ${ }^{1}$, Peter C. Coyte ${ }^{2}$ \\ ${ }^{1}$ Wuhan University of Technology \\ 122 Luoshi Road, Wuhan, Hubei, P.R. China \\ E-mail.jiaoli.cai@mail.utoronto.ca,zhaohz@mail.whut.edu.cn \\ ${ }^{2}$ University of Toronto \\ 155 College Street, Suite 425, Toronto, ON M5T 3M6, Canada \\ E-mail.jiaoli.cai@mail.utoronto.ca,peter.coyte@utoronto.ca \\ cross $^{\text {ref }}{ }^{\text {http://dx.doi.org/10.5755/j01.ee.29.1.16878 }}$
}

\begin{abstract}
Research on the relationship between intellectual property rights (IPR) protection and economic growth and innovation has often been explored. However, there is an absence of research dealing with the relationship between IPR protection and the international competitiveness of high-tech industries, especially the pharmaceutical manufacturing industry. This study aims to examine the impact of the strength of IPR protection on the international competitiveness of China's pharmaceutical manufacturing industry, by using time series data from 1995 to 2014. A modified Ginarte-Park (GP) index is used to measure the strength of IPR protection, while the revealed comparative advantage (RCA) index is used to measure the international competitiveness of China's pharmaceutical manufacturing industry. A multivariate time series model and ordinary least squares (OLS) estimation are employed to examine the relationship between IPR protection and the RCA index. The results show that strict IPR protection does not enhance the international competitiveness of China's pharmaceutical manufacturing industry. The finding suggests that it is more appropriate to adopt a more relaxed IPR protection system for the pharmaceutical manufacturing industry in China. The finding may also provide a reference for countries which have similar backgrounds.
\end{abstract}

Keywords: High-Tech Industry; Pharmaceutical Manufacturing; Intellectual Property Rights; Industrial Competitiveness; Technological Innovation.

\section{Introduction}

In the context of economic globalization and the rapid development of technology, the world economy is shifting from the traditional economy, characterized by raw materials, capital and a lot of energy, to the information and knowledge-oriented economy. The knowledge economy uses data as its raw material and transforms it using technology, analytic tools and human intelligence into knowledge and competence (Snieska \& Draksaite, 2007). Intellectual property rights (IPR), which are characterized by patents, play an important role in the knowledge economy and are important for a country's competitiveness (Zheng \& Song, 2012). However, IPR protection can impact the economy in two ways (Zheng \& Song, 2012). On the one hand, strengthening IPR protection can spur innovation, reduce the cost of follow-on innovations, thus promoting economic growth. On the other hand, strengthening IPR protection can hinder technology diffusion between countries, weaken competition, and thus, hindering economic growth.

The pharmaceutical manufacturing industry, which is considered to be a high-tech industry, is not only an important part of the national economy, but also plays an important role in national health, social and economic development, and national security. Products of the modern pharmaceutical manufacturing industry have improved the care for patients afflicted with many disorders. Drug manufacturers have been successful in the translation of discoveries to successful products (Henry \& Lexchin, 2002). In the pharmaceutical manufacturing industry, China has demonstrated its strong imitation capability, but has been weak in its innovation capability. Pharmaceutical manufacturing industry itself has a long cycle of research and development (R\&D). The technology of pharmaceutical manufacturing industry in China is mainly imported from abroad, rather than relying on independent R\&D.

China, as a developing country, represents an interesting case study. On the one hand, China's pharmaceutical manufacturing industry plays an important role in the world. China is the second largest world producer of pharmaceutical ingredients, with an annual output of 800,000 tonnes in 2003. Chinese firms rank first in the world in the production of five pharmaceutical chemicals: penicillin, vitamin $\mathrm{C}$, terramycin, doxycycline hydrochloride and cephalosporins (Grace, 2004). On the other hand, however, it seems that China is unable to compete with the established global giants head-on in the global market (Yeung, 2002). We wonder whether or not the IPR protection, which is the most distinctive feature in the knowledge-based economy, plays a role in the international competitiveness of China's pharmaceutical manufacturing industry. Thus, the purpose of this study is to explore the relationship between the strength of IPR protection and the 
international competitiveness of pharmaceutical manufacturing industry in China. In addition, other factors affecting the competitiveness of China's pharmaceutical manufacturing industry are also investigated.

\section{Theoretical and Empirical Evidence}

The earliest links between IPR protection and $\mathrm{c}$ competition date back to the resource-based theory of Barney (1991) and Porter's (1990) diamond model. Based on Barney's theory, sustainable competitive advantages come from the valuable, scarce and irreplaceable resources. The novelty and creativity of the patent also makes the patent difficult to be replaced in a certain period of time. The scarcities of IPR can bring a competitive advantage to a country. Some scholars reported that IPR is the cornerstone of a country's competitiveness (Zheng \& Song, 2012). Porter (1990) also indicated that competitive advantage lies not only in specific resources, but also in the use and management of these resources and the ability to create value. IPR as a special resource has timeliness, which determines that its development, accumulation and updates can bring sustainable competitive advantages.

Empirical analyses on the relationship between IPR protection, economic growth and innovation have reported mixed findings. Some studies found that IPR protection had a positive impact on economic growth. Gould \& Gruben (1996) using cross-country data on patent protection, trade regime, and country-specific characteristic, examined the role of IPR protection in economic growth. They found that IPR protection was a significant determinant of economic growth. In order to examine the impact of IPR protection on economic growth and welfare, Kwan \& Lai (2003) employed an expandingvariety-type R\&D-based endogenous growth model to the US data. They found that in the case of over-protection, the welfare losses were trivial; whereas in the case of underprotection, the welfare losses could be substantial. Dinopoulos \& Kottaridi (2008) constructed a two-country (innovative North and imitating South) model of productcycle trade, fully endogenous Schumpeterian growth, and national patent policies. They found that stronger global IPR protection could accelerate the rate of international technology transfer and increase the rates of global innovation and growth.

However, some scholars found that strengthening IPR protection hindered economic growth and technology diffusion. Helpman (1992) reported that strengthening IPR protection in southern countries (technological imitation countries) would not be conducive to technological imitation, thus hindering economic development in southern countries. Sener (2006) constructed a North-South product cycle model of trade and explored the global effects of strengthening Southern IPR protection. They found that this strengthening reduced rates of innovation and imitation.

Further, complex relationships between economic growth, innovation and IPR protection were also revealed by other studies. Schneider (2005) found that the growth effect of IPR protection depended on the level of per capita GDP. Only after per capita GDP reached a certain level would IPR protection have a positive impact on economic growth. Schneider also found that IPR protection affected the innovation rate, but this impact was more significant in developed countries. Hudson \& Minea (2013) investigated the association between IPR protection and innovation, by combining the effect of the initial level of IPR protection and the level of economic development in a single, unified, empirical framework. They found that the effect of IPR protection on innovation was more complex than previously thought, and displayed important nonlinearities, i.e. it depended on the initial levels of both IPR protection and per capita GDP. Falvey et al. (2006) investigated the impact of IPR protection on economic growth in a panel of 79 countries using threshold regression analysis. They found that the effect of IPR protection on growth depended upon the level of development. IPR protection was positively and significantly correlated with growth for lowand high-income countries, but not for middle-income countries. Similar findings have been also reported by Kim et al. (2012). Allred \& Park (2007) reported a U-shaped relationship between IPR protection and technological innovation in developed countries, but no relationship between them in developing countries.

According to the literature, several problems remain to be settled. First, while most of the previous studies have focused on the relationship between IRP protection and economic growth and innovation, no consistent conclusion has been reached. Generally, it seems that strengthening IPR protection can promote innovation for developed countries, while it may hinder innovation for the developing countries. New evidence should be provided to examine this. Second, there is a paucity of research addressing the association between IRP protection and the international competitiveness of high-tech industry, especially for pharmaceutical manufacturing industry in developing countries.

Our study will fill these gaps by conducting an empirical analysis of the relationship between IPR protection and the international competitiveness of China's pharmaceutical manufacturing industry over the two decades from 1995 to 2014.

This study may contribute to the literature in a number of ways. First, to the best of our knowledge, this is the first study to examine the relationship between IPR protection and the international competitiveness of China's pharmaceutical manufacturing industry. Second, by conducting our empirical application in a developing country rather than the customary approach that has considered IPR protection within developed countries, our study will offer an alternative perspective; Third, the findings from our study may provide a reference for other developing countries with similar backgrounds to China.

\section{Methodology}

\section{International Competitiveness of the Pharmaceutical Manufacturing Industry}

The dependent variable in the current study is the international competitiveness of the pharmaceutical manufacturing industry.

Chen \& Tan (2004) suggested that the essence of industrial competitiveness was based on four components: source; essence; performance; and results. They advanced 
four methods to evaluate each of these four aspects of industrial competitiveness: multi-factor methods; international comparison of output productivity (ICPO) methods; import and export data methods; and industry profit methods. Among them, the most popular method was the import and export data method, which measured competitive performance, i.e. market share. The revealed comparative advantage (RCA) index, which belongs to the import and export method, has often been used to measure the international competitiveness of certain industries in some countries (Ferto \& Hubbard, 2003; Serin \& Civan, 2008; Utkulu \& Seymen, 2004). In our study, we will use the RCA index to measure the international competitiveness of China's pharmaceutical manufacturing industry.

RCA was proposed by Balassa (1965). RCA of a nation is measured by the relative weight of a percentage of total export of commodity's in a nation over the percentage of world export in that commodity. It can better reflect the relative advantages of one country's exports compared to the average level of exports in the world. $\mathrm{RCA}$ is calculated as follows:

$$
R C A_{i j}=\left(X_{i j} / X_{i t}\right) /\left(X_{w j} / X_{w t}\right)
$$

Where $X_{i j}$ and $X_{w j}$ are the values of country $i$ 's exports of commodity $j$ and world exports of commodity $j$ and where $X_{i t}$ and $X_{w t}$ refer to the country's total exports and world total exports. So, the RCA index of country $i$ for commodity $j$ is measured by the commodity $j$ 's share in the country's exports in relation to its share in world trade. A value of less than 1 implies that the country has a revealed comparative disadvantage in the commodity. Similarly, if the index exceeds 1 , the country is said to have a revealed comparative advantage in the commodity. In this study, $X_{i j}$ stands for the pharmaceutical manufacturing exports in China; $X_{i t}$ stands for China's total exports of goods; $X_{w j}$ represents the pharmaceutical manufacturing exports in the world; and $X_{w t}$ represents the world's total exports of goods.

In order to assess the reliability of our estimates, we also use the revealed competitiveness (RC) index proposed by Vollrath (1991) to measure international competitiveness. The RC index does not rely only on exports but rather also incorporates imports. The $\mathrm{RC}$ is given by the formula:

$$
\begin{aligned}
& R C_{i j}=\operatorname{Ln}\left[\left(X_{i j} / X_{i t}\right) /\left(X_{w j} / X_{w t}\right)\right]-\operatorname{Ln}\left[\left(M_{i j} / M_{i t}\right) /\right. \\
& \left.\left(M_{w j} / M_{w t}\right)\right]
\end{aligned}
$$

Where $X_{i j}, X_{i t}, X_{w j}, X_{w t}$ are defined as before in equation (1), while $M_{i j}$ represents imports to country $i$ of commodity $j, M_{i t}$ represents the sum of imports to country $i, M_{w j}$ represents the world's imports of commodity $j$, and $M_{w t}$ represents total imports for the world. $L n$ represents the natural logarithm. A positive $\mathrm{RC}$ reflects a comparative/competitive advantage, whereas a negative value reflects a comparative/competitive disadvantage. In our study, $M_{i j}$ stands for the pharmaceutical manufacturing imports to China; $M_{i t}$ stands for China's total imports of goods; $M_{w j}$ represents pharmaceutical manufacturing imports for the world; and $M_{w t}$ represents the world's total imports of goods.

\section{The Strength of Intellectual Property Right (IPR) Protection}

The main independent variable in the current study is the strength of intellectual property right (IPR) protection.

Previous studies have used three main methods to measure the strength of IPR protection. First, to use a questionnaire to evaluate assessments based on the opinions of managers, patent lawyers and other related employees (Mansfield, 1995; Sherwood, 1996). Second, to use a legislative grading method to evaluate national IPR legislation (Rapp \& Rozek, 1990; Ginarte \& Park, 1997), and finally, a comprehensive evaluation method that integrates the other two methods into a single comprehensive grading system (Kondo, 1995; Lesser, 2001). At present, Ginarte-Park (GP) method, as a legislative grading method, advanced by Ginarte \& Park, (1997) has been the dominant method used by scholars (Braga \& Fink, 1999; Falvey et al., 2006; Javorcik, 2004; Kumar, 2001). It overcomes the deficiency of an alternative legislative grading method proposed by Rapp \& Rozek (1990), and avoids the subjectivity associated with the surveys of opinions. The GP ${ }^{1}$ method contains five indicators: (1) extent of coverage; (2) membership in international patent agreements; (3) provisions for loss of protection; (4) enforcement mechanisms; and (5) duration of protection. Each of these categories is scored from 0 to 1 . The unweighted sum of these five scores constitutes the overall value of the GP index. The index therefore ranges in value from zero to five. Higher values of the index indicate stronger levels of IPR protection (Ginarte \& Park, 1997).

Han \& Li (2005) calculated the strength of IPR protection in China according to the GP method, but found that the results did not comply with China's reality. They noted that the GP method only measured the legislation strength of China's IPR, but did not measure the strength of IPR protection. For the western countries, where there exists a relatively sound legal system, the strength of IPR protection can be calculated by the GP index. However, countries like China that are in transition with respect to their legal systems, the strength of IPR protection measured by the legislative indicator (GP index) may be inaccurate. As a consequence, the GP method has been modified by adding an enforcement index. The enforcement strength of IPR protection is based on four components $^{2}$ : (1) the degree of social legalization; (2) the degree of perfection in the legal system; (3) the level of economic development; and (4) the supervision and balance mechanisms in the international community (Han $\& \mathrm{Li}, 2005)$. The enforcement index ranges from 0 to 1 , with 0 representing situations where the IPR-related laws have not been executed, while 1 indicates a situation where the laws have been fully executed. Xu \& Dan (2008) have also proposed an index to measure the enforcement

\footnotetext{
${ }^{1}$ For a detailed description of the GP method, see http://www.sciencedirect.com/science/article/pii/S004873339700 $\underline{022 X}$

${ }^{2}$ For a detailed description of Han and Li's method, see http://www.cqvip.com/qk/96310x/200302/1001100288.html
} 
strength of IPR, and their index contains five components ${ }^{3}$ : (1) the level of judicial protection; (2) the level of administrative protection and management; (3) the level of economic development; (4) public awareness; and (5) the supervision and balance mechanisms in the international community. This enforcement index value also ranges from 0 to 1 . The strength of China's IPR protection may then be defined as the product between the enforcement index and the index measuring the legislation strength of IPR. Consequently, the formula used in our study to assess the strength of IPR protection in China is defined as:

$$
P(t)=L(t) * E(t)
$$

Where $P(t)$ represents the strength of IPR protection in year $t . L(t)$ stands for the legislation strength of IPR in year $t$ and $E(t)$ represents the enforcement strength of IPR in year $t$. In the current study, we use the GP index (Ginarte \& Park, 1997) to measure the legislation strength of IPR, while the Xu and Dan's method (Xu \& Dan, 2008) is used to measure the enforcement strength of IPR.

\section{Model}

The diamond model of Porter is the basic theoretical model for analysing the potential influence factors of competitiveness. According to the diamond model, four attributes are related to competitiveness: factors of production; demand condition; related and supporting industries; and corporate strategy and structure. Government and opportunities also play important roles in industrial competition (Porter, 1990). Technological innovation has been also recognized as a key factor affecting international competitiveness (Dosi \& Soete, 1991; Galovic, 2015; Mihi-Ramirez et al., 2016). Pharmaceutical manufacturing industry is knowledgeintensive. Based on this characteristic of pharmaceutical manufacturing industry, Shabaninejad et al. (2014) identified several key factors affecting the competitiveness of pharmaceutical manufacturing industry. Their findings also provide support for the choice of influencing potential factors that affect the international competitiveness of pharmaceutical manufacturing industry in China. Based on the above factors, and considering data availability, we use the factors of production, technological innovation, and government support as potential factors.

Factors of production includes capital inputs, human resource inputs and knowledge inputs. We use $R \& D$ funding intensity, R\&D personnel intensity and patent density, which respectively stand for the capital inputs, human resource inputs and knowledge inputs, to measure factors of production. R\&D funding intensity is the ratio of $R \& D$ expenditures to the total value of pharmaceutical manufacturing production. $R \& D$ personnel intensity is the ratio of the number of internal $R \& D$ personnel to the total number of employees in pharmaceutical manufacturing. Patent density is measured by the number of patents per 100 employees in pharmaceutical manufacturing.

\footnotetext{
${ }^{3}$ For a detailed description of Xu and Dan's method, see http://www.cqvip.com/qk/93202x/200804/28047545.html
}

Government supports include financial support and environmental support. Financial support is measured by the ratio of health expenditure to total national fiscal expenditure. Environmental support is measured by the strength of IPR protection.

R\&D funding intensity, R\&D personnel intensity, patent density, government financial support and the strength of IPR protection also correspond to the three aspects of technological innovation process: technological innovation inputs, technological innovation outputs, and technological innovation environment.

Therefore, the regression model is constructed as follows:

$R C A_{t}=\beta_{0}+\beta_{1} I P R P_{t}+\beta_{2} R D S_{t}+\beta_{3} R D P_{t}+$

$\beta_{4} P D_{t}+\beta_{5} G S_{t}+\mu_{t}$

Where $R C A_{t}$ represents the international competitiveness of pharmaceutical manufacturing industry in year $t ; I P R P_{t}$ stands for the strength of IPR protection; $R D S_{t}$ represents the $\mathrm{R} \& \mathrm{D}$ funding intensity; $R D P_{t}$ represents the R\&D personnel intensity; $P D_{t}$ stands for patent density; $G S_{t}$ stands for the government financial support; and $\mu_{t}$ is the random error term for year $\mathrm{t}$. $\beta_{1}, \beta_{2}, \beta_{3}, \beta_{4}$ and $\beta_{5}$ are the effects of $I P R P_{t}, R D S_{t}, R D P_{t}$, $P D_{t}$, and $G S_{t}$, respectively. When using the RC index to measure competitiveness, the left-hand side of equation (4) is $R C_{t}$.

\section{Data Source}

The RCA and RC indices are based on export and import trade data for China and the world derived from the Organisation for Economic Co-operation and Development $(\mathrm{OECD})^{4}$, World Trade Organization (WTO) ${ }^{5}$ and International Monetary Fund (IMF) ${ }^{6}$ official websites. The values related to the strength of IPR protection are calculated based on data derived from the Chinese Intellectual Property Rights Yearbook (State Intellectual Property Office of the P.R.C, 1996-2015). R\&D funding intensity, $R \& D$ personnel intensity, patent density and government financial support are based on data drawn from the China Statistics Yearbook (National Bureau of Statistics of the People 's Republic of China, 1996-2015), China Science and Technology Yearbook (National Bureau of Statistics of the People 's Republic of China, 1996-2015), and the China Statistics Yearbook on High Technology Industry (National Bureau of Statistics of the People 's Republic of China, 2015).

\section{Statistical Analysis}

We employ multivariate time series and ordinary least squares (OLS) regression methods on two decades of data from 1995 to 2014. All analyses are conducted using Stata, version 13.0. Descriptive analysis regarding changes to the competitiveness of the pharmaceutical manufacturing industry and changes to the strength of IPR protection are performed. The results are shown in Figure 1, Table 1 and

\footnotetext{
${ }^{4}$ OECD website: http://www.oecd.org

${ }^{5}$ WTO website: https://www.wto.org

${ }^{6}$ IMF website: http://www.imf.org/external/index.htm
} 
Figure 2. We then conduct unit root tests with the results presented in Table 2. When using time-series regression methods a stationary process for each time-series is required. If the time series is nonstationary (or has unit root), it is necessary to test the first order difference of the time series. If the first order difference of time series is a stationary process, it is called " integrated of order one". In the current study, we use the most effective method (DFGLS test) to test for unit roots. The original hypothesis underlying the DF-GLS test is that the time series has unit root (or is nonstationary) (Elliott et al., 1996). To ensure that our results are robust, we also use another method to test for unit roots, i.e. the KPSS method, whose primary assumption is that each time series is stationary (Kwiatkowski et al., 1992). After assessing stationarity, we employ the Johansen test for cointegration between the variables. The basic idea behind cointegration is that nonstationary variables may share a common stochastic trend that may be eliminated by taking a linear combination of the variables (Berisha et al., 2015). The generalization of the Johansen test requires an examination of linear combinations of variables for unit roots. This test is used to examine whether there is a long-term equilibrium relationship between the dependent variable and the independent variables. We report the results of the trace test and the maximum eigenvalue test from the Johansen test in Table 3. Finally, we employ multivariate time series and OLS regression methods. The White and Durbin-Watson (DW) tests are used to examine whether there exists heteroscedasticity and autocorrelation, respectively. The results of the OLS analysis are presented in the first column of Table 4 . We also conduct robust tests with the results shown in the second and third columns of Table 4. When RC index is used to measure competitiveness, the results are presented in Table 5.

\section{Results and Discussion}

\section{Results}

Figure 1 reports trends in the RCA index for China's pharmaceutical manufacturing industry from 1995 to 2014. Over the last two decades the value of the RCA index has been less than 1, and has declined almost continuously. As a result, China has a comparative disadvantage in the pharmaceutical manufacturing industry and its competitiveness is decreasing.

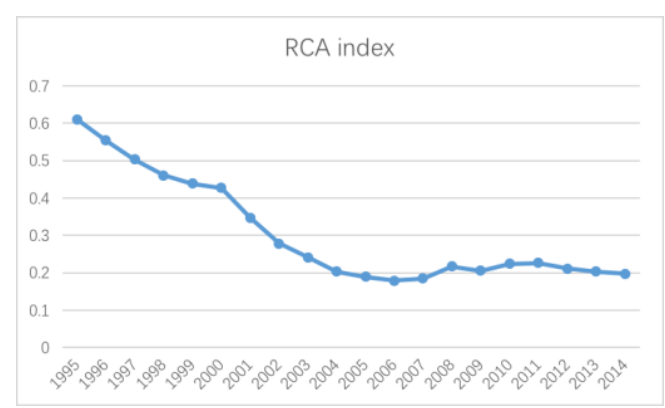

Figure 1. Trends of the RCA index of China's pharmaceutical manufacturing industry, 1995-2014.
Table 1 and Figure 2 report on the strength of IPR protection from 1995 to 2014 in China. The strength of IPR protection increased over the last two decades and has been driven more by improvements in enforcement $(E(t))$ than by the growth in legislative strength $(\mathrm{L}(\mathrm{t}))$.

Table 1

\section{Strength of China's Intellectual Property Protection} (1995 to 2014)

\begin{tabular}{|c|c|c|c|}
\hline Year & $\mathbf{L}(\mathbf{t})$ & $\mathbf{E}(\mathbf{t})$ & $\mathbf{P}(\mathbf{t})$ \\
\hline 1995 & 3.023 & 0.3666 & 1.1082 \\
\hline 1996 & 3.153 & 0.4014 & 1.2657 \\
\hline 1997 & 3.273 & 0.4336 & 1.4192 \\
\hline 1998 & 3.273 & 0.473 & 1.5481 \\
\hline 1999 & 3.403 & 0.508 & 1.7287 \\
\hline 2000 & 3.403 & 0.5694 & 1.9377 \\
\hline 2001 & 4.19 & 0.5932 & 2.4855 \\
\hline 2002 & 4.19 & 0.6292 & 2.6363 \\
\hline 2003 & 4.524 & 0.6484 & 2.9334 \\
\hline 2004 & 4.524 & 0.6834 & 3.0917 \\
\hline 2005 & 4.524 & 0.7102 & 3.2129 \\
\hline 2006 & 4.524 & 0.7422 & 3.3577 \\
\hline 2007 & 4.524 & 0.7424 & 3.3586 \\
\hline 2008 & 4.524 & 0.7488 & 3.3876 \\
\hline 2009 & 4.524 & 0.7576 & 3.4273 \\
\hline 2010 & 4.524 & 0.7702 & 3.4844 \\
\hline 2011 & 4.524 & 0.7768 & 3.5142 \\
\hline 2012 & 4.524 & 0.781 & 3.5332 \\
\hline 2013 & 4.524 & 0.7856 & 3.5541 \\
\hline 2014 & 4.524 & 0.7902 & 3.5717 \\
\hline
\end{tabular}

Notes: $L(t)$, legislation strength of IPR; $E(t)$, enforcement strength of IPR; $P(t)$, strength of IPR protection.

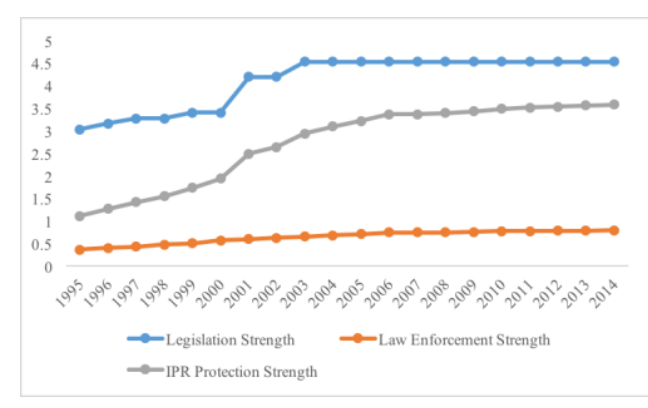

Figure 2. Changes of the strength of China's IPR Protection, 1995-2014.

Table 2 presents the results of the unit root tests. Because the original time series are nonstationary, the first order difference of the original time series is tested. The results show that the first order difference is stationary, that is, it is integrated of order one.

Cointegration between variables is assessed based on the Johansen test, the results of trace test, and the maximum eigenvalue test are presented in Table 3. The results of the trace statistic with a constant term and time trend show that there is one long-run equilibrium relationship between the dependent variable and the independent variables (the result with an asterisk in Table 3). The maximum eigenvalue test also indicates that the original hypothesis of "cointegration rank 0 " is rejected at the $5 \%$ significance level $(72.0642>39.37)$. But the 
Jiaoli Cai, Hongzhong Zhao. The Effect of Intellectual Property Rights Protection on the International Competitiveness of....

hypothesis of "cointegration rank 1" cannot be rejected $(22.8576<33.46)$. Therefore, it can be concluded that there is a long-term stable equilibrium relationship between the dependent variable and the independent variables.

Table 2

Unit Root Test

\begin{tabular}{|c|c|c|c|c|c|c|c|c|}
\hline Variables & $\begin{array}{c}\text { Differential } \\
\text { times }\end{array}$ & $\mathbf{( T , \mathbf { K } )}$ & $\mathbf{D F}-\mathbf{G L S}$ & Critical value & $\mathbf{( T , \mathbf { K } )}$ & KPSS & Critical value & Conclusion \\
\hline RCA & 1 & $(\mathrm{~T}, 1)$ & -2.185 & $-1.936^{*}$ & $(\mathrm{~T}, 2)$ & 0.154 & $0.216^{* * *}$ & $\mathrm{I}(1)$ \\
\hline RC & 1 & $(\mathrm{~T}, 1)$ & -2.926 & $-2.660^{* *}$ & $(\mathrm{~T}, 2)$ & 0.139 & $0.146^{* *}$ & $\mathrm{I}(1)$ \\
\hline IPRP & 1 & $(0,0)$ & -2.548 & $-2.250^{* *}$ & $(0,1)$ & 0.601 & $0.739^{* * *}$ & $\mathrm{I}(1)$ \\
\hline GS & 1 & $(0,1)$ & -2.997 & $-2.692^{*}$ & $(0,1)$ & 0.656 & $0.739^{* * *}$ & $\mathrm{I}(1)$ \\
\hline RDS & 1 & $(0,1)$ & -1.714 & $-1.600^{*}$ & $(0,1)$ & 0.229 & $0.463^{* *}$ & $\mathrm{I}(1)$ \\
\hline RDP & 1 & $(0,1)$ & -2.838 & $-2.660^{* * *}$ & $(0,1)$ & 0.442 & $0.739^{* * *}$ & $\mathrm{I}(1)$ \\
\hline PD & 1 & $(0,2)$ & -1.789 & $-1.600^{*}$ & $(0,1)$ & 0.427 & $0.739^{* * *}$ & $\mathrm{I}(1)$ \\
\hline
\end{tabular}

Notes: *** $p<0.01, * * p<0.05, * p<0.1 ; T, K$, respectively, represents the time trend and the lag order; $I(1)$ indicates integrated of order one.

Table 3

Johansen Tests For Cointegration

\begin{tabular}{|c|c|c|c|c|c|}
\hline Maximum rank & Parms & LL & Eigenvalue & Trace statistic & 5 \% critical value \\
\hline 0 & 6 & 77.717638 & $\cdot$ & 135.7878 & 94.15 \\
\hline 1 & 17 & 113.74975 & 0.97747 & $63.7236^{*}$ & 68.52 \\
\hline 2 & 26 & 125.17857 & 0.69972 & 40.866 & 47.21 \\
\hline 3 & 33 & 135.50478 & 0.66276 & 20.2135 & 29.68 \\
\hline 4 & 38 & 141.85728 & 0.48762 & 7.5085 & 15.41 \\
\hline 5 & 41 & 145.19304 & 0.29611 & 0.837 & 3.76 \\
\hline 6 & 42 & 145.61155 & 0.0431 & & Max statistic \\
\hline Maximum rank & Parms & LL & Eigenvalue & 72.0642 & 39.37 \\
\hline 0 & 6 & 77.717638 & & 22.8576 & 33.46 \\
\hline 1 & 17 & 113.74975 & 0.97747 & 20.6524 & 27.07 \\
\hline 2 & 26 & 125.17857 & 0.69972 & 12.705 & 20.97 \\
\hline 3 & 33 & 135.50478 & 0.66276 & 6.6715 & 14.07 \\
\hline 4 & 38 & 141.85728 & 0.48762 & 0.837 & \\
\hline 5 & 41 & 145.19304 & 0.29611 & & 3.76 \\
\hline
\end{tabular}

Notes: * indicates the hypothesis is tested at $5 \%$ significant levels. Parms, Parameter Estimation; LL, Maximum likelihood.

Table 4 shows the regression results. The OLS regression results are presented in the first column. Heteroscedasticity and autocorrelation are absent from the first column based on results of the White test $(\mathrm{P}=0.3946)$ and the DW test $(\mathrm{DW}=1.9492)$. From the first column, the strength of IPR protection is shown to be negatively related to the international competitiveness of China's pharmaceutical manufacturing industry. The results demonstrate that a one percentage point increase in the strength of IPR protection in the pharmaceutical manufacturing industry would reduce the international competitiveness of China's pharmaceutical manufacturing industry by 0.252 percentage points. The government's finicial support, $R \& D$ funding inputs and the patent density are positively correlated with the international competitiveness of China's pharmaceutical manufacturing industry. If $R \& D$ funding intensity, patent density and government support increase by one percentage point, the international competitiveness of China's pharmaceutical manufacturing industry would increase by $0.0395,0.310$, and 0.117 percentage points, respectively. R\&D personnel input is negatively associated with the international competitiveness of China's pharmaceutical manufacturing industry. A one percentage point increase in the intensity of R\&D personnel inputs would result in a competitiveness reduction of 0.103 percentage points. In order to conduct robust tests, the results of the OLS with robust standard errors and the results of OLS with cluster robust standard errors are respectively presented in the second and third columns of Table 4. All the results are consistent.

Table 4

\section{Regression Results for RCA}

\begin{tabular}{|c|c|c|c|}
\hline & $\mathbf{( 1 ) O L S}$ & $\mathbf{( 2 ) O L S + r}$ & $\mathbf{( 3 ) O L S + c l u s t e r}$ \\
\hline Variables & RCA & RCA & RCA \\
\hline IPRP & $-0.252^{* * *}$ & $-0.252^{* * *}$ & $-0.252^{* * *}$ \\
\hline & $(-11.10)$ & $(-12.14)$ & $(-12.14)$ \\
\hline RDS & $0.0395^{*}$ & $0.0395^{* * *}$ & $0.0395^{* * *}$ \\
\hline & $(1.13)$ & $(5.30)$ & $(5.30)$ \\
\hline RDP & $-0.103^{*}$ & $-0.103^{*}$ & $-0.103^{* *}$ \\
\hline & $(-2.40)$ & $(-2.91)$ & $(-2.91)$ \\
\hline PD & $0.310^{*}$ & $0.310^{*}$ & $0.310^{*}$ \\
\hline & $(1.22)$ & $(1.81)$ & $(1.81)$ \\
\hline GS & $0.117^{* * *}$ & $0.117^{* * *}$ & $0.117^{* * *}$ \\
\hline & $(5.10)$ & $(4.69)$ & $(4.69)$ \\
\hline cons & $0.695^{* * *}$ & $0.695^{* * *}$ & $0.695 * * *$ \\
\hline & $(6.63)$ & $(7.89)$ & $(7.89)$ \\
\hline R-squared & 0.9748 & 0.9748 & 0.9748 \\
\hline F & 108.42 & 76.73 & 76.73 \\
\hline N & 20 & 20 & 20 \\
\hline
\end{tabular}

Notes: $t$-statistics in parentheses; $* * * p<0.01, * * p<0.05, * p<0.1$. 


\section{Robustness Test}

We also use RC index to measure competitiveness in order to assess how robust our results. Based on the unit root test, we find that the original time series for the $\mathrm{RC}$ index is nonstationary, but the first order difference of RC index is stationary, i.e. I(1) (Table 2). Based on the Johansen test, we find that there is a long-term stable equilibrium relationship between the $\mathrm{RC}$ index and the independent variables. Table 5 shows the regression results when using the RC index. The results are consistent with the results in Table 4 . We again confirm our findings.

Table 5

Regression Results for RC

\begin{tabular}{|c|c|c|c|}
\hline & $\mathbf{( 1 ) O L S}$ & $\mathbf{( 2 ) O L S + r}$ & $\mathbf{( 3 ) O L S + c l u s t e r}$ \\
\hline Variables & $\mathrm{RC}$ & $\mathrm{RC}$ & $\mathrm{RC}$ \\
\hline IPRP & $-0.161^{* * *}$ & $-0.161^{* * *}$ & $-0.161^{* * *}$ \\
\hline & $(-6.17)$ & $(-5.68)$ & $(-5.68)$ \\
\hline RDS & $0.0706^{* *}$ & $0.0706^{* * *}$ & $0.0706^{* * *}$ \\
\hline & $(1.75)$ & $(4.55)$ & $(4.55)$ \\
\hline RDP & $-0.183^{* * *}$ & $-0.183^{* * *}$ & $-0.183^{* * *}$ \\
\hline & $(-3.68)$ & $(-3.94)$ & $(-3.94)$ \\
\hline PD & $0.423^{*}$ & $0.423^{*}$ & $0.423^{*}$ \\
\hline & $(1.45)$ & $(1.74)$ & $(1.74)$ \\
\hline GS & $0.145^{* * *}$ & $0.145^{* * *}$ & $0.145^{* * *}$ \\
\hline & $(5.49)$ & $(4.34)$ & $(4.34)$ \\
\hline cons & $0.254^{*}$ & $0.254^{*}$ & $0.254^{*}$ \\
\hline & $(2.11)$ & $(1.78)$ & $(1.78)$ \\
\hline R-squared & 0.961 & 0.961 & 0.961 \\
\hline F & 68.66 & 110.63 & 110.63 \\
\hline N & 20 & 20 & 20 \\
\hline
\end{tabular}

Notes: $t$-statistics in parentheses; $* * * p<0.01, * * p<0.05, * p<0.1$.

\section{Discussion}

Our results show that strengthening IPR protection in China does not enhance the international competitiveness of the pharmaceutical manufacturing industry. This result is consistent with the finding by Allred \& Park (2007) that demonstrated for developing countries, that IPR protection was not conducive to technological innovation. Shapiro (2001) also found that the strong IPR protection was not conducive to technological innovation. China is a developing country and lacks independent innovation in its pharmaceutical manufacturing. China's pharmaceutical manufacturing industry relies on imitative innovation. The strong IPR protection system hinders imitative innovation. $R \& D$ funding inputs and patent intensity can promote innovation; they can promote the competitiveness of industries. Our results that technological innovation can promote competitiveness are consistent with the previous findings (Morgan \& Cooke, 1998; Nelson \& Phelps, 1966). It needs to be noted, however, that $R \& D$ personnel input does not promote the competitiveness of China's pharmaceutical manufacturing industry. This may be because China's R\&D personnel are mainly distributed among the country's public research institutes, and are mostly engaged in the basic R\&D activities. Only a few people work in enterprises as $R \& D$ personnel. There are some time lags to apply these research results to the enterprise's new products to enhance the international competitiveness of products. In China, the government can be the main driving force to promote the development of certain industries. That explains why government financial support has an important impact on industrial competitiveness in China. This is also in line with Porter's finding that government plays an important role in the development of industries (Porter, 1990).

There are several study limitations that warrant highlighting. First, we only use two indicators to measure competitiveness. Multiple measures of competitiveness should be considered in the future. However, the two indicators we choose are commonly used in the literature. Second, the variables selected for use in our study are based on those used in the literature. The Porter's Diamond model and the study by Shabaninejad et al. (2014) summarize the factors that influence the pharmaceutical industry. We may have omitted some potential variables, but we have controlled for the important influencing factors that may affect competitiveness. Third, the findings here may not necessarily generalize to other developed countries. However, the findings may provide a reference for other developing countries that have a similar background to China.

\section{Conclusions and Policy Implications}

In the current study, by using GP method to calculate the legislation strength of IPR, and Xu and Dan's method to measure the enforcement strength of IPR, we calculate the strength of China's IPR protection for the last two decades from 1995 to 2014 . We find that the strength of IPR protection in China has increased each year, while the international competitiveness of China's pharmaceutical manufacturing industry has fallen over the study period.

Several main findings are obtained from the current study. First, strict IPR protection does not enhance the international competitiveness of pharmaceutical manufacturing in China. Second, innovative investments and outputs are important factors that promote the competitiveness of this industry. Third, the government's support for this industry can have an important impact on its competitiveness.

Our findings may be easier to understand if they are combined with China's reality. China became a member of the WTO in 2001, which means that China needs to fully implement a series of WTO agreements, including the Agreement on Trade-Related Aspects of Intellectual Property Rights (TRIPs). Therefore, China revised its patent laws in 2001 and strengthened legislation on IPR protection, in order to conform to the international regulations. As shown in Figure 2, the legislation strength of IPR shows a pronounced upward trend since 2000 to 2001. However, more and more international scholars criticized TRIPs and thought that they may be harmful to developing countries (Lanoszka, 2003; Weissman, 2004). Chinese scholars also reported that strong IRP protection is conducive to technological innovation in developing countries including China (Wang, 2011). Strong IRP protection may have hindered imitative innovation which is an important factor for the survival of pharmaceutical enterprises in China. Thus, the international competitiveness of China's pharmaceutical industry shows a downward trend over the study years with the continuous 
strengthening of IPR protection. Our findings may provide a possible explanation for China's current situations.

Our findings have several possible policy implications. First, it is difficult to drive the technological leap of hightech industry depending on the same strength of IPR protection and the same IPR system. The more realistic approach is based on the characteristics of different industries, to design different management systems of IPR which are in line with industrial characteristics. Kanwar \& Envenson (2003) indicated that there will be practical significance if the relationship between IPR and technological innovation can be researched regarding different industries. The pharmaceutical manufacturing industry itself has the characteristic of long R\&D cycle, and the level of independent innovation of China's pharmaceutical manufacturing industry is low. Technological progress of pharmaceutical manufacturing industry much more depends on imitating foreign advanced technologies. So, it is more appropriate to adopt a more relaxed IPR protection system in China. Second, the government should increase efforts to support the pharmaceutical manufacturing industry and make full use of its fiscal measures to increase innovation subsidies for pharmaceutical manufacturing, especially for the biomedical industry. The government should also adjust policies appropriately, and increase support on the independent research-based pharmaceutical manufacturing industry. Third, it is important to increase investment in technological innovation. Increasing investment in R\&D funding, encouraging employees to actively innovate and to apply for patents, will contribute to the development of pharmaceutical manufacturing industry and promote industrial competitiveness.

\section{References}

Allred, B. B., \& Park, W. G. (2007). Patent rights and innovative activity: evidence from national and firm-level data. Journal of International Business Studies, 38(6), 878-900. http://link.springer.com/article/10.1057/palgrave.j $\underline{\text { ibs.8400306 }}$

Balassa, B. (1965). Trade liberalisation and "revealed" comparative advantage1. The Manchester School, 33(2), 99-123. http://onlinelibrary.wiley.com/doi/10.1111/j.1467-9957.1965.tb00050.x/abstract

Barney, J. (1991). Firm resources and sustained competitive advantage. Journal of management, 17(1), 99-120. http://journals.sagepub.com/doi/abs/10.1177/014920639101700108

Berisha, E., Meszaros, J., \& Olson, E. (2015). Income inequality and household debt: a cointegration test. Applied Economics Letters, 22(18), 1469-1473. http://www.tandfonline.com/doi/abs/10.1080/13504851.2015.1039698

Braga, C. P., \& Fink, C. (1999). How stronger protection of intellectual property rights affects international trade flows. World Bank Policy Research Working Paper, (2051). https://papers.ssrn.com/sol3/papers.cfm?abstract_id=569254

Chen, LM., \& Tan, LW. (2004). Empirical method of the evaluation of international competitiveness of Chinese manufacturing industry - Comparison of Porter's index and industrial classification. China Industrial Economics, (5), $30-37$.

Dosi, G., \& Soete, L. (1991). Technological Innovation and International. Technology and National Competitiveness, 91.

Dinopoulos, E., \& Kottaridi, C. (2008). The growth effects of national patent policies. Review of International Economics, 16(3), 499-515. https://doi.org/10.1111/j.1467-9396.2008.00742.x

Elliott, G., Rothenberg, T. J., \& Stock, J. H. (1996). Efficient tests for an autoregressive unit root. Econometrica, 64(4), 813-836. http://www.jstor.org/stable/2171846?seq=1\#page_scan_tab_contents https://doi.org/10.2307/2171846

Falvey, R., Foster, N., \& Greenaway, D. (2006). Intellectual property rights and economic growth. Review of Development Economics,10(4), 700-719. http://onlinelibrary.wiley.com/doi/10.1111/j.1467-9361.2006.00 343.x/full

Ferto, I., \& Hubbard, L. J. (2003). Revealed comparative advantage and competitiveness in Hungarian agri-food sectors. The World Economy, 26(2), 247-259. http://onlinelibrary.wiley.com/doi/10.1111/1467-9701.00520/full

Galovic, T. (2015). The international competitiveness of the pharmaceutical industry within 21 OECD countries. Ekonomski Vjesnik/Econviews: Review of contemporary business, entrepreneurship and economic issues, 28(1), 225-241. http://hrcak.srce.hr/140840

Ginarte, J. C., \& Park, W. G. (1997). Determinants of patent rights: A cross-national study. Research policy, 26(3), 283301. http://www.sciencedirect.com/science/article/pii/S004873339700022X

Gould, D. M., \& Gruben, W. C. (1996). The role of intellectual property rights in economic growth. Journal of development economics, 48(2), 323-350. http://www.sciencedirect.com/science/article/pii/0304387895000399

Grace, C. (2004). The effect of changing intellectual property on pharmaceutical industry prospects in India and China. DFID Health Systems Resource Centre, 1-68. http://www.who.int/hiv/amds/Grace2China.pdf?ua=1 
Han YX, \& Li HZ. (2005). Quantitative analysis of the level of intellectual property protection in China. Studies in Science of Science, 23(3), 377-382.

Helpman, E. (1992). Innovation, imitation, and intellectual property rights (No. w4081). National Bureau of Economic Research. http://www.nber.org/papers/w4081

Henry, D., \& Lexchin, J. (2002). The pharmaceutical industry as a medicines provider. The Lancet, 360(9345), 15901595. http://www.sciencedirect.com/science/article/pii/S0140673602115273

Hudson, J., \& Minea, A. (2013). Innovation, intellectual property rights, and economic development: A unified empirical investigation. World Development, 46, 66-78. http://www.sciencedirect.com/science/article/pii/S0305750X1 3000296

Javorcik, B. S. (2004). The composition of foreign direct investment and protection of intellectual property rights: Evidence from transition economies. European economic review, 48(1), 39-62. http://www.sciencedirect.com/ science/article/pii/S001429210200257X

Kanwar, S., \& Evenson, R. (2003). Does intellectual property protection spur technological change?. Oxford Economic Papers, 55(2), 235-264. http://oep.oxfordjournals.org/content/55/2/235.short

Kim, Y. K., Lee, K., Park, W. G., \& Choo, K. (2012). Appropriate intellectual property protection and economic growth in countries at different levels of development. Research policy, 41(2), 358-375. http://dx.doi.org/10.1 016/j.respol.2011.09.003

Kondo, E. K. (1995). The effect of patent protection on foreign direct investment. Journal of World Trade, 29(6), 97-122. http://www.kluwerlawonline.com/document.php?id=TRAD1995044

Kumar, N. (2001). Determinants of location of overseas R\&D activity of multinational enterprises: the case of US and Japanese corporations. Research Policy, 30(1), 159-174. http://dx.doi.org/10.1016/S0048-7333(99)00102-X

Kwan, Y. K., \& Lai, E. L. C. (2003). Intellectual property rights protection and endogenous economic growth. Journal of Economic Dynamics and Control, 27(5), 853-873. http://dx.doi.org/10.1016/S0165-1889(02)00018-0

Kwiatkowski, D., Phillips, P. C., Schmidt, P., \& Shin, Y. (1992). Testing the null hypothesis of stationarity against the alternative of a unit root: How sure are we that economic time series have a unit root?. Journal of econometrics, 54(1-3), 159-178. http://www.sciencedirect.com/science/article/pii/030440769290104Y

Lanoszka, A. (2003). The global politics of intellectual property rights and pharmaceutical drug policies in developing countries. International Political Science Review, 24(2), 181-197. http://journals.sagepub.com/doi/abs/ 10.1177/019 2512103024002002

Lesser, W. (2001). The effects of TRIPS-mandated intellectual property rights on economic activities in developing countries. World Intellectual Property (WIPO) Studies, 1, 1-24. http://www.wipo.int/export/sites/www/aboutip/en/studies/pdf/ssa_lesser_trips.pdf

Mansfield, E. (Ed.). (1995). Intellectual property protection, direct investment, and technology transfer: Germany, Japan, and the United States (Vol. 27). World Bank Publications. https://doi.org/10.1596/0-8213-3442-5

Mihi-Ramirez, A., Garcia-Rodriguez, Y., \& Cuenca-Garcia, E. (2016). Innovation and International High Skilled Migration. Inzinerine Ekonomika-Engineering Economics, 27(4), 452-461. https://doi.org/10.5755/j01.ee.27.4. 14396

Morgan, K., \& Cooke, P. (1998). The Associational Economy: Firms, Regions, and Innovation (SSRN Scholarly Paper No. ID 1496189). Rochester, NY: Social Science Research Network. https://papers.ssrn.com/abstract=1496189

National Bureau of Statistics of the People 's Republic of China. China Statistical Yearbook. Beijing: China Statistics Press,1995-2015. http://www.stats.gov.cn/tjsj/ndsj/

National Bureau of Statistics of the People 's Republic of China. China Statistics Yearbook on High Technology Industry. Beijing: China Statistics Press, 2015. http://www.stats.gov.cn/tjsj/tjcbw/201111/t20111130_451564.html

National Bureau of Statistics of the People 's Republic of China. China Statistical Yearbook on Science and Technology. Beijing: China Statistics Press,1995-2015. http://www.stats.gov.cn/tjsj/ndsj/

Nelson, R. R., \& Phelps, E. S. (1966). Investment in humans, technological diffusion, and economic growth. The American economic review, 56(1/2), 69-75. http://www.jstor.org/stable/1821269

Porter, M. E. (1990). The competitive advantage of notions. Harvard business review 68(2), 73-93.

Rapp, R. T., \& Rozek, R. P. (1990). Benefits and costs of intellectual property protection in developing countries. Journal of world trade, 24(5), 75-102. http://www.kluwerlawonline.com/document.php?id=TRAD1990033 
Jiaoli Cai, Hongzhong Zhao. The Effect of Intellectual Property Rights Protection on the International Competitiveness of....

Schneider, P. H. (2005). International trade, economic growth and intellectual property rights: A panel data study of developed and developing countries. Journal of Development Economics, 78(2), 529-547. http://dx.doi.org/10.1016/ j.jdeveco.2004.09.001

Sener, F. (2006). Intellectual property rights and rent protection in a North-South product-cycle model. Manuscript, Union College, Schenectady. http://minerva.union.edu/senerm/Research/Sener_IPRs_Rent_Protection_PAPER_July_06.pdf

Serin, V., \& Civan, A. (2008). Revealed comparative advantage and competitiveness: A case study for Turkey towards the EU. Journal of Economic and Social Research, 10(2), 25-41. http://citeseerx.ist.psu.edu/viewdoc/download? doi=10.1.1.568.1868\&rep=rep1\&type $=$ pdf

Shabaninejad, H., Mehralian, G., Rashidian, A., Baratimarnani, A., \& Rasekh, H. R. (2014). Identifying and prioritizing industry-level competitiveness factors: evidence from pharmaceutical market. DARU Journal of Pharmaceutical Sciences, 22(1), 35. https://darujps.biomedcentral.com/articles/10.1186/2008-2231-22-35.

Shapiro, C. (2001). Navigating the patent thicket: Cross licenses, patent pools, and standard setting. In Innovation Policy and the Economy, Volume 1 (pp. 119-150). MIT press. https://doi.org/10.2139/ssrn.273550

Sherwood, R. M. (1996). Intellectual property systems and investment stimulation: The rating of systems in eighteen developing countries. Idea, 37, 261.

Snieska, V., \& Draksaite, A. (2007). The role of knowledge process outsourcing in creating national competitiveness in global economy. Inzinerine Ekonomika-Engineering Economics(3), 35-41. https://www.ceeol.com/search/articledetail?id=183080

State Intellectual Property Office of the P.R.C. China Intellectual Property Rights Yearbook. Beiijng: Intellectual Property Press, 1995-2015. http://www.sipo.gov.cn

Utkulu, U., \& Seymen, D. (2004, September). Revealed Comparative Advantage and Competitiveness: Evidence for Turkey vis-a-vis the EU/15. In European trade study group 6th annual conference, ETSG. http://web.deu.edu.tr/ ab/MAKALE/deu MAK/0006.pdf

Vollrath, T. L. (1991). A theoretical evaluation of alternative trade intensity measures of revealed comparative advantage. Weltwirtschaftliches Archiv, 127(2), 265-280. http://link.springer.com/article/10.1007/BF02707986

Wang, H. (2011). Are stronger intellectual property protection systems conducive to technological innovation? Economic Research, S2 (2011), 124-135.

Weissman, R. (2004). A long, strange TRIPS: The pharmaceutical industry drive to harmonize global intellectual property rules, and the remaining WTO legal alternatives available to third world countries. U. Pa. J. Int'l Econ. L., $25,1079$. http://heinonline.org/HOL/LandingPage?handle=hein.journals/upjiel17\&div=43\&id=\&page=

$\mathrm{Xu}, \mathrm{CM} .$, \& Dan, XG. (2008). Construction and verification of the index system for the strength of intellectual property rights protection in China. Studies in Science of Science, 26(4), 715-723.

Yeung, G. (2002). The implications of WTO accession on the pharmaceutical industry in China. Journal of Contemporary China, 11(32), 473-493. http://www.tandfonline.com/doi/abs/10.1080/10670560220152292

Zheng, YL., \& Song, H. (2012). An Empirical Research on the Impact of China's Intellectual Property Protection on Competitiveness of Chinese High-tech Industry. China Soft Science, (2),147-155.

The article has been reviewed. Received in November, 2016; accepted in February, 2018. 